\title{
Effects of Choline Deficiency and Phosphatidylcholine on Fat Absorption in Rats
}

\author{
Yukari TAKAHASHI, Toshimi MizUnUmA, and Yasuo KISHINO ${ }^{1}$ \\ Department of Nutrition, School of Medicine, Tokushima \\ University, 3 Kuramoto-cho, Tokushima 770, Japan \\ (Received July 30, 1981)
}

\begin{abstract}
Summary Transfer of lipid to the lymph by the intestine was studied in rats fed on choline-deficient or choline-supplemented diet for 2 weeks. In choline-deficient rats, lymph output was reduced. Choline deficiency impaired the incorporation of glycerol tri[ $\left[1{ }^{14} \mathrm{C}\right]$ oleate into triglyceride in the lymph. The triglyceride level in lymph lipoproteins was lower in choline-deficient rats than in controls. Ultrastructural studies suggested that impaired release of lipoproteins was responsible for accumulation of fat in intestinal absorptive cells. These defects are probably related to changes in the membrane system of the intestine and to a failure in lipid droplet movement within absorptive cells, resulting from alterations in the microfilaments. Oral administration of phosphatidylcholine to rats on choline-deficient diet rapidly improved the decreased lymph output and the impaired incorporation of glycerol tri[ $\left[1-{ }^{14} \mathrm{C}\right]$ oleate into triglyceride and reduced fat deposition in intestinal epithelial cells. In conclusion, phospholipids such as choline are confirmed as being extremely important in the absorption of fat by the possible mechanism of fat transport across the membrane.

Key Words fat absorption, choline deficiency, lymphatic output, phosphatidylcholine, corn oil, chylomicron, electron microscopy, intestinal epithelial cell
\end{abstract}

The role of choline in the transport of lipoproteins from the intestine to the lymph is unknown. O'Doherty et al. (1973)(l) suggested that dietary choline is important in fat absorption by providing precursors of phosphatidylcholine for chylomicron formation. In the present work we examined the effect of choline deficiency and addition of phosphatidylcholine to the diet on the secretion and composition of intestinal lymph during fat absorption. Lipid secretion was assayed by measuring incorporation of glycerol tri $\left[1{ }^{14} \mathrm{C}\right]$ oleate into lymph triglyceride. Electron microscopic studies were made on the impaired intracellular transport of

${ }^{1}$ 高橋 因, 水沼俊美, 岸野泰雄 
lipid droplets and secretion of chylomicrons at the level of Golgi complex in relation to disorganization of microfilaments within absorptive cells.

\section{MATERIALS AND METHODS}

Animals. Male Wistar strain rats weighing 80 to $90 \mathrm{~g}$ were housed in individual cages. They were given water and food ad libitum and kept in an air-conditioned room at $22 \pm 2{ }^{\circ} \mathrm{C}$. The compositions of their diets are shown in Table 1 . These diets were given for 2 weeks, the following experiments then being carried out.

The rats were starved for $15 \mathrm{hr}$ and anesthetized by an intraperitoneal injection of sodium pentobarbital ( $400 \mathrm{mg} / \mathrm{kg}$ body weight). Then $2 \mathrm{ml}$ of corn oil, $2 \mathrm{ml}$ of corn oil containing $10 \mu \mathrm{Ci}$ glycerol tri[ $\left.1-{ }^{14} \mathrm{C}\right]$ oleate (Radiochemical Centre, Amersham) or $2 \mathrm{ml}$ of corn oil containing $300 \mathrm{mg}$ of phosphatidylcholine was infused by stomach tube. One hour later, a midline incision of the abdomen was made and the main intestinal lymph duct was cannulated with clear silicious tubing (OD. $0.5 \mathrm{~mm}$, Dow Corning Corp. Medical Products, Midland, MI) using the method of Bollman et al. (2). Lymph was collected in centrifuge tubes immersed in ice for $3 \mathrm{hr}$ and the volume was recorded.

Analytical procedures. Lipid was extracted from lymph by the procedure of Folch et al. (3). Triglyceride was then measured by the method of Fletcher (4), total cholesterol by the ferric chloride-sulfuric acid method of Zak (5), phospholipid by the method of Bartlett (6) and free fatty acids by that of Itaya and Ui(7). Protein concentration in lipoproteins was determined by the method of Lowry et al. (8). The radioactivity of intestinal lymph-lipids was measured after extracting them into $5 \mathrm{ml}$

Table 1. Composition of diets.

\begin{tabular}{lcc}
\hline \multicolumn{1}{c}{ Component } & Choline-supplemented & Choline-deficient \\
& \multicolumn{2}{c}{ (weight \%) } \\
\hline Vitamin-free casein $^{\mathrm{a}}$ & 15 & 15 \\
Corn starch $^{\mathrm{a}}$ & 60 & 60 \\
Corn oil $^{\mathrm{b}}$ & 20 & 20 \\
Salt mixture $^{\mathrm{a}, \mathrm{c}}$ & 4 & 4 \\
Vitamin mixture $^{\mathrm{a}}$ & 1 & 1 \\
Vitamin A $^{\mathrm{d}}$ & $3,000 \mathrm{I} . \mathrm{U}$ & $3,000 \mathrm{I} . \mathrm{U}$ \\
Vitamin D $^{\mathrm{d}}$ & $7.5 \mu \mathrm{g}$ & $7.5 \mu \mathrm{g}$ \\
$\alpha$-Tocopherol & $10 \mathrm{mg}$ & $10 \mathrm{mg}$ \\
Choline chloride & $200 \mathrm{mg}$ & $0 \mathrm{mg}$ \\
\hline
\end{tabular}

${ }^{\text {a }}$ Oriental Yeast Co., Ltd., Tokyo, Japan. ${ }^{\mathrm{b}}$ Nakarai Chemical Co., Ltd., Kyoto, Japan.

' Percentage composition: $\mathrm{CaHPO}_{4} \cdot \mathrm{H}_{2} \mathrm{O}, 14.56 ; \mathrm{KH}_{2} \mathrm{PO}_{4}, 25.72 ; \mathrm{NaH}_{2} \mathrm{PO}_{4} \cdot \mathrm{H}_{2} \mathrm{O}, 9.35$;

$\mathrm{NaCl}$, 4.66; Ca-lactate, 35.09; Fe-citrate, 3.18; $\mathrm{MgSO}_{4}, 7.17 ; \mathrm{ZnCO}_{3}, 0.11 ; \mathrm{MnSO}_{4}, 0.12$; $\mathrm{CuSO}_{4} \cdot 5 \mathrm{H}_{2} \mathrm{O}, 0.03$; KI, 0.01. ${ }^{\mathrm{d}}$ Eisai Co., Ltd., Tokyo, Japan. Amounts per $100 \mathrm{~g}$ of diet; vitamin A as retinyl palmitate, 3,000 I.U; vitamin D as ergocalciferol, 300 I.U. 
of Dole's reagents (9). Then $3 \mathrm{ml}$ of heptane and $2 \mathrm{ml}$ of water were added. The mixture was vigorously shaken and centrifuged and $3 \mathrm{ml}$ of the upper heptane layer was mixed with $3 \mathrm{ml}$ of $0.05 \mathrm{~N} \mathrm{NaOH}$ in $50 \%$ ethanol. The mixture was centrifuged and the radioactivity of the heptane layer was determined in an ALOKA LSC-703 liquid scintillation counter. Counts were converted to disintegration rates (dpm).

Polyacrylamide gel electrophoresis was carried out by a modification of the method of Davis (10). Lymph was prestained with Sudan black B and electrophoresis was carried out with gel concentrations of 5 and $3 \%$ for the main gel and $1.875 \%$ for the spacer gel. Prestained lymph was mixed with 5 volumes of $40 \%$ sucrose and $50 \mu \mathrm{l}$ of the mixture were applied to the top of the spacer and carefully overlayed with $0.05 \mathrm{M}$ Tris-glycine buffer, $\mathrm{pH}$ 8.3. Electrophoresis was performed at a current of $2 \mathrm{~mA}$ per tube.

Electron microscopy. Fresh intestinal tissues were promptly fixed in $2.5 \%$ glutaraldehyde in $0.1 \mathrm{M}$ phosphate buffer, $\mathrm{pH} 7.4$, for $2 \mathrm{hr}$ and postfixed in $2 \%$ osmium tetroxide in $0.1 \mathrm{M}$ phosphate buffer for $1 \mathrm{hr}$ at $4^{\circ} \mathrm{C}$. The tissues were then washed repeatedly with $0.1 \mathrm{M}$ phosphate buffer, dehydrated in a graded series of acetone and embedded in Epon 812 and 815 mixture. Ultrathin sections were stained with uranyl acetate and lead citrate, and examined using a Hitachi HU-12 electron microscope.

\section{RESULTS}

\section{Lymph output}

Lymph output was low in starved rats, but increased after fat infusion. The output throughout the experiment was lower in the choline-deficient rats $(0.78 \pm 0.08 \mathrm{ml} / 3 \mathrm{hr})$ than in the controls $(1.50 \pm 0.10 \mathrm{ml} / 3 \mathrm{hr})$ (Fig. 1).

\section{Lipoprotein composition of lymph}

Lymph was collected for $2 \mathrm{hr}$ after corn oil infusion. The lipoproteins in the

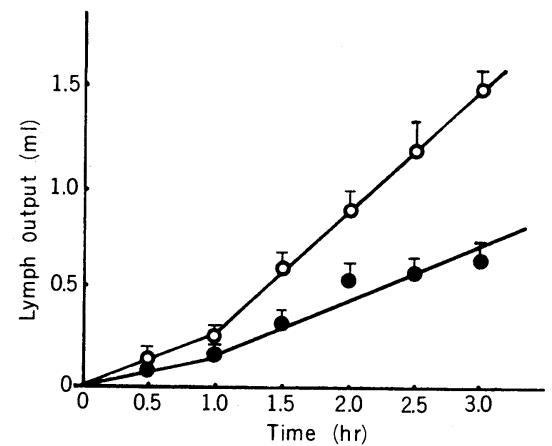

Fig. 1. Time course of output of intestinal lymph. Lymph was collected from five rats fed on choline-supplemented diet $(\bigcirc)$ or choline-deficient diet $(\bullet)$ every $30 \mathrm{~min}$ for $3 \mathrm{hr}$. 
Table 2. Disc electrophoretic pattern of intestinal lymph lipoprotein after administration of corn oil to rats on choline-deficient and choline-supplemented diets.

\begin{tabular}{lcc}
\hline Lipoprotein & \multicolumn{2}{c}{$\begin{array}{c}\text { Choup } \\
(\% \text { distribution })\end{array}$} \\
\hline Chylomicrons & $37.0 \pm 1.3$ & $22.9 \pm 2.6^{*}$ \\
VLDL & $15.0 \pm 1.1$ & $18.0 \pm 4.6$ \\
LDL & $27.3 \pm 1.5$ & $39.5 \pm 3.0^{*}$ \\
HDL & $13.2 \pm 2.7$ & $12.5 \pm 2.0$ \\
Alb-NEFA & $7.5 \pm 0.0$ & $7.1 \pm 0.8$ \\
\hline
\end{tabular}

Intestinal lymph was prestained for $1 \mathrm{hr}$, and separated by polyacrylamide gel electrophoresis as described in "MATERIALS AND METHODS." Abbreviations: VLDL, very low density lipoprotein; LDL, low density lipoprotein; HDL, high density lipoprotein; Alb-NEFA, albumin-bound free fatty acid. Values are means \pm SE for 5 rats. * Difference from the corresponding value for rats fed on choline-supplemented diet statistically significant $(p<0.05)$.

Table 3. Compositions of intestinal lymph lipoproteins after administration of corn oil to rats on choline-deficient or choline-supplemented diets.

\begin{tabular}{|c|c|c|c|}
\hline Lipid & Group & Choline-supplemented & Choline-deficient \\
\hline TG & & $45.8 \pm 3.0$ & $35.8 \pm 2.6^{*}$ \\
\hline PL & & $8.6 \pm 1.0$ & $7.8 \pm 0.9$ \\
\hline Cho & & $1.8 \pm 0.3$ & $1.4 \pm 0.5$ \\
\hline FFA & & $1.7 \pm 0.2$ & $1.4 \pm 0.1$ \\
\hline Prot & & $51.6 \pm 5.1$ & $58.4 \pm 5.4$ \\
\hline
\end{tabular}

Analytical methods are described in "MATERIALS AND METHODS." Abbreviations: TG, triglyceride; PL, phospholipid; Cho, cholesterol; FFA, free fatty acid; Prot, protein. Values are means \pm SE for 5 rats. ${ }^{*}$ Difference from the corresponding value for rats fed on choline-supplemented diet statistically significant $(p<0.05)$.

lymph were classified into four types (Table 2): chylomicrons, very low density lipoprotein (VLDL), low density lipoprotein (LDL) and high density lipoprotein (HDL). In choline-deficient rats, the percentage of chylomicrons was significantly lower and the percentage of LDL significantly higher than in rats on cholinesupplemented diet.

As shown in Table 3, triglyceride was a major component of intestinal lymph. In choline-deficient rats there was a significant decrease in triglyceride $(p<0.05)$ and slight decreases in phospholipid and cholesterol in lymph lipoprotein. The reduced content of triglyceride seemed to reflect a decrease in the amount of chylomicrons in the lymph of choline-deficient rats. 

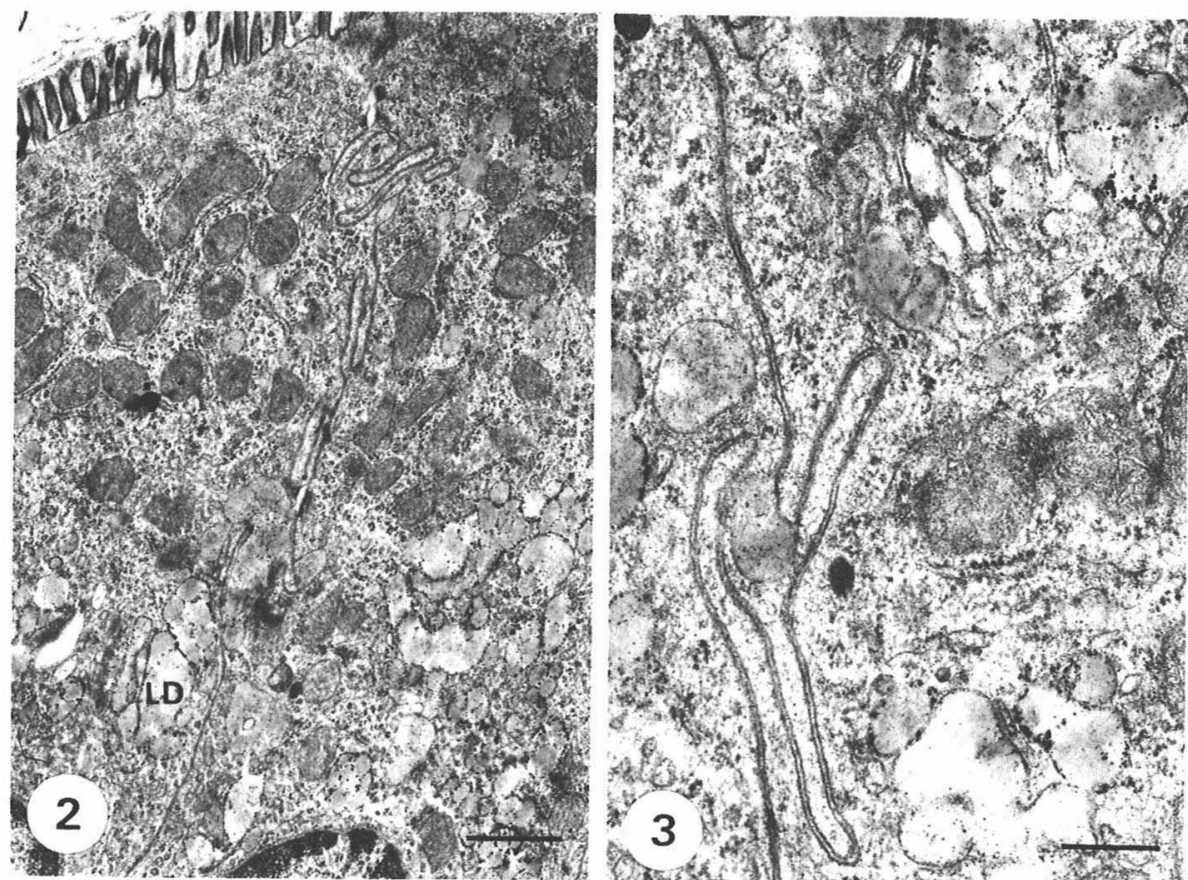

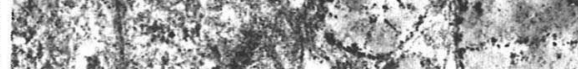
mot.t.

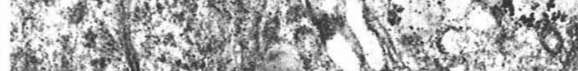

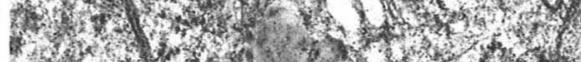

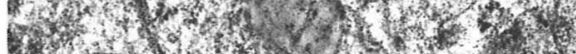

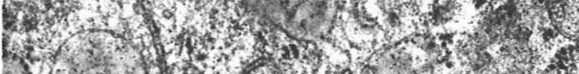

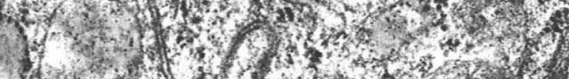

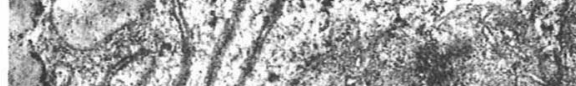

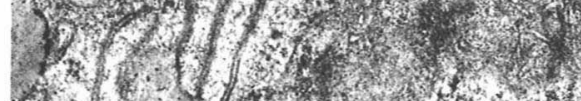
A

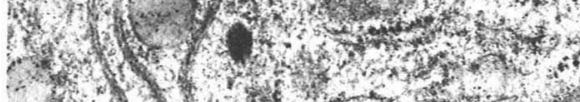

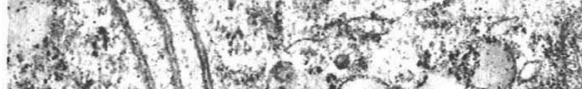
2.

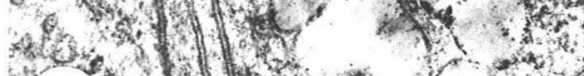

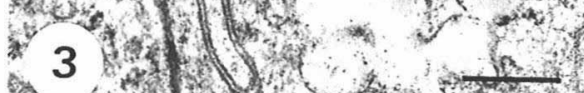
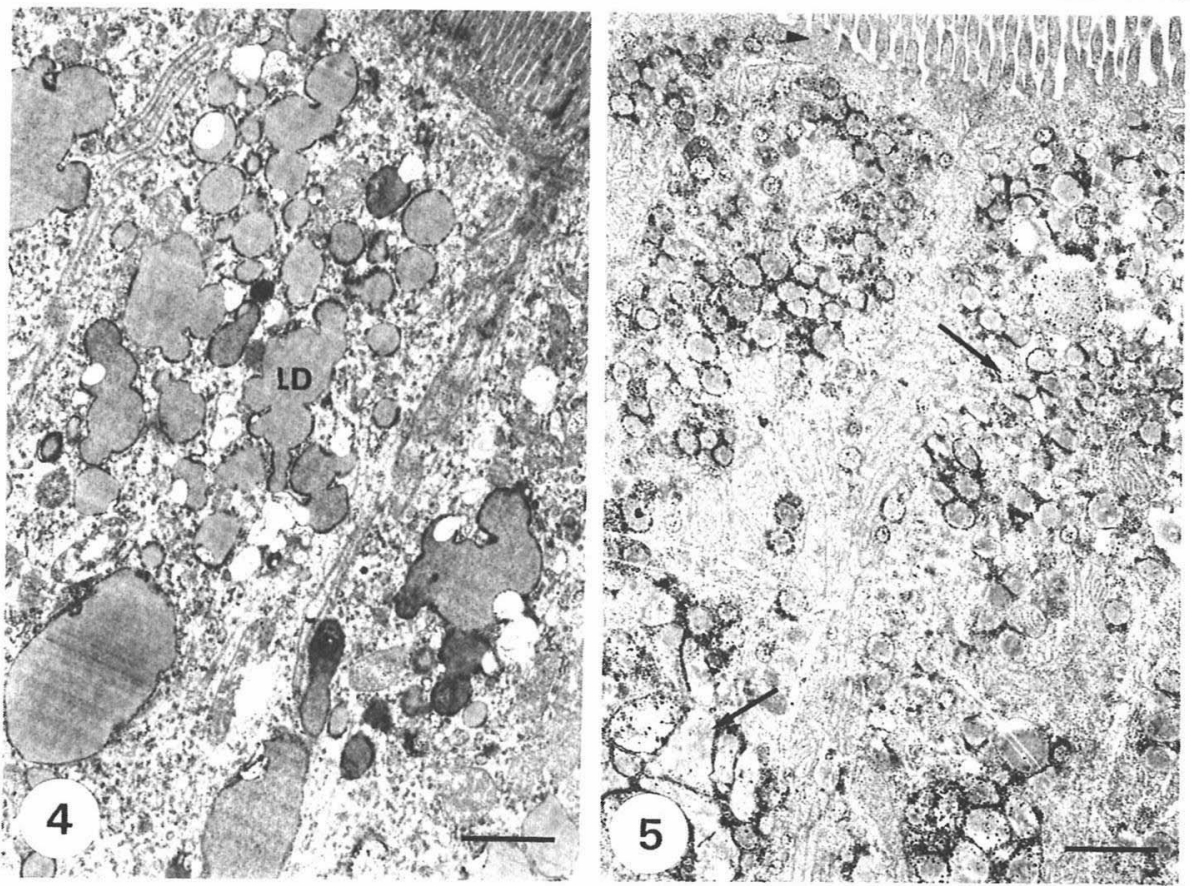

Vol. 28, No. 2, 1982 
Table 4. Effect of phosphatidylcholine on incorporation of ${ }^{14} \mathrm{C}$-triglyceride into intestinal lymph.

\begin{tabular}{clll}
\hline Group & Treatment & \multicolumn{1}{c}{$\begin{array}{c}{ }^{14} \mathrm{C}-\mathrm{TG} \\
(\mathrm{dpm} / \mathrm{ml})\end{array}$} & $\begin{array}{c}\text { TG } \\
(\mathrm{mg} / \mathrm{ml})\end{array}$ \\
\hline \multirow{2}{*}{$\mathrm{CS}$} & Corn oil & $332,010 \pm 10,610$ & $43.0 \pm 3.8$ \\
& Corn oil + PC & $480,550 \pm 31,303^{* *}$ & $55.1 \pm 6.6^{* *}$ \\
\hline \multirow{2}{*}{$\mathrm{CD}$} & Corn oil & $236,686 \pm 20,486^{*}$ & $22.6 \pm 0.4^{*}$ \\
& Corn oil +PC & $589,730 \pm 148,550^{* *}$ & $58.8 \pm 2.7^{* *}$ \\
\hline
\end{tabular}

A volume of $2 \mathrm{ml}$ of corn oil plus $10 \mu \mathrm{Ci}$ of glycerol tri $\left[1-{ }^{14} \mathrm{C}\right]$ oleate $(49 \mathrm{mCi} / \mathrm{mmol})$ was infused by stomach tube as described in "MATERIALS AND METHODS," and total lymph was collected from the main intestinal lymph duct for $2 \mathrm{hr}$. Abbreviations: TG, triglyceride; CS, choline-supplemented; CD, choline-deficient; $\mathrm{PC}$, phosphatidylcholine. Values are means \pm SE for 5 rats. ${ }^{*}$ Difference from the corresponding value for rats on choline-supplemented diet statistically significant $(p<0.05)$. ${ }^{* *}$ Difference from the corresponding value for rats given corn oil only statistically significant $(p<0.05)$.

After infusion of labeled triolein into the stomach, the amount of radioactive triglyceride was measured in the lymph collected at intervals over $2 \mathrm{hr}$. In rats given phosphatidylcholine, more radioactive triolein was incorporated into triglyceride of lymph than in rats infused with corn oil only. This effect was greater in cholinedeficient rats than in controls (Table 4).

\section{Electron microscopy}

Three hours after fat administration, the Golgi complex of absorptive cells of

Fig. 2. Electron micrograph of an intestinal absorptive cell $3 \mathrm{hr}$ after corn oil administration. Several lipid droplets are seen in the SER. RER is present in the region between the SER and mitochondria. Smaller lipid droplets are also observed in the RER. In Golgi complex and intercellular spaces, lipid appears in vacuoles as small droplets (LD), similar in size to those in the SER. SER, smooth endoplasmic reticulum; RER, rough endoplasmic reticulum. Bar, $1 \mu \mathrm{m}$.

Fig. 3. Higher magnification of the area near the Golgi complex and lateral plasma membrane of Fig. 2. Bar, $0.3 \mu \mathrm{m}$.

Fig. 4. Electron micrograph of the cytoplasm of an absorptive cell from a cholinedeficient rat $3 \mathrm{hr}$ after corn oil administration. The most prominent feature is the presence of large irregular-shaped droplets of lipid (LD), which are frequently seen near the Golgi complex. The amounts of RER and mitochondria are reduced in the cytoplasm. Bar, $1 \mu \mathrm{m}$.

Fig. 5. Intestinal absorptive cells from a choline-deficient rat $3 \mathrm{hr}$ after administration of corn oil with phosphatidylcholine. Smaller round droplets of lipid are seen throughout the cytoplasm. Golgi vacuoles and intercellular spaces also contain discrete droplets of the same size (arrow) as those in the SER of the apical cytoplasm. Large mitochondria and RER are frequent. Bar, $1 \mu \mathrm{m}$. 
control rats was found to contain a few small lipid droplets in the supranuclear area and along the lateral plasma membranes (Fig. 2). The intercellular space adjacent to the region of the Golgi complex and to the base of the absorptive cells contained lipid droplets of similar size to those seen in the Golgi complex (Fig. 3). These droplets were also found in the lacteals and seemed to be chylomicrons. Much rough endoplasmic reticulum and many mitochondria appeared in the cytoplasm.

In choline-deficient rats (Fig. 4), much lipid accumulated in the cytoplasm of intestinal absorptive cells. The larger droplets probably resulted from fusion of several smaller droplets of lipid and sometimes displayed large irregular figures in the cytoplasm. These figures frequently occurred near the Golgi complex, which had many vacuoles containing lipid droplets. Golgi vacuoles were greatly dilated and contained lipid, but Golgi saccules were rare. There was much less rough endoplasmic reticulum than in control rats. Chylomicrons were seen in intercellular spaces and lacteals of choline-deficient rats after fat administration. No lipid was present in the intercellular spaces above the level of the Golgi complex.

Three hours after administration of fat with phosphatidylcholine, small round lipid droplets were prominent throughout the cytoplasm of absorptive cells (Fig. 5). Golgi vacuoles usually contained several discrete droplets similar in size to those in the apical cytoplasm: only rarely did a single large lipid droplet fill the entire vacuole.

\section{DISCUSSION}

In this work we compared morphological findings on intestinal cells with biochemical data on lipid in intestinal lymph during fat absorption in rats given choline-deficient and choline-supplemented diets. Many investigators (11-15) have indicated that lipid particles within the smooth endoplasmic reticulum are synthesized from triglyceride and phospholipid, cholesterol and protein molecules. Indeed, in ultracytochemical studies, Higgins and Barnett (16) demonstrated that monoglyceride acyltransferase is localized mainly on the inner surface of the smooth endoplasmic reticulum. It has been suggested that after their synthesis, phospholipids diffuse to the contiguous smooth endoplasmic reticulum where they are used to form new reesterified triglyceride. Phospholipids are also used for the production of new membranes in the cells. As observed morphologically, the final stage in intracellular fat transport is fusion of smooth endoplasmic reticulum vesicles with the lateral cell membrane and concomitant release of completed chylomicrons into the intercellular space $(11,14)$. At this stage, lipid droplets must pass through the Golgi complex before they are released. Redgrave (17) reported that the membrane component of the prechylomicron fraction contains phospholipase and triglyceride lipase, which might act on Golgi and plasma membrane phospholipid to cause fusion of the two membranes and subsequent release of the lipid contained in the Golgi vacuoles. This implies a constant loss of Golgi membranes as chylomicrons are produced and released from absorptive cells, and suggests that maintenance of

Vol. 28, No. 2, 1982 
the Golgi complex requires replacement of its membrane components during fat absorption(18). Electron micrographs of material from choline-deficient rats showed dilatation of vesicles of the smooth endoplasmic reticulum and vacuoles of the Golgi complex, but no defect in these membranes. The rate of lymph flow and the triglyceride content of the lymph diminished during fat infusion. However, the phospholipid content of the lymph only decreased slightly. This may be a direct result of the decreased availability of phospholipid. On the other hand, as previously reported (19), retardation of intestinal lipid secretion in choline deficiency also results directly or indirectly from impairment of microfilament function in absorptive cells. Phospholipid composed of choline is important for myosin ATPase activity in the intestinal absorptive cells during fat absorption, linked to the contraction mechanism of microfilaments. In the present work, administration of phosphatidylcholine to choline-deficient rats improved the lymphatic output from the intestine and accelerated the movement of lipoproteins from the epithelial cells, across intercellular spaces and through the lacteals. After phosphatidylcholine administration there was also a significant increase in incorporation of glycerol tri[ $\left[1{ }^{14} \mathrm{C}\right]$ oleate into triglyceride in the intestinal lymph.

We conclude from this work that choline deficiency delays secretion of lipid into the lymph by promoting its accumulation in the absorptive cells. After phosphatidylcholine administration, the outputs of total lipid and triglyceride-rich lipoproteins increased.

The authors are deeply indebted to Mr. Michimasa Fujimoto and Mr. Tatsuo Kashiyama of the electron microscope facility for his technical help.

\section{REFERENCES}

1) O'Doherty, P. J. A., Kakis, G., and Kuksis, A. (1973): Role of luminal lecithin in intestinal fat absorption. Lipids, 8, 249-255.

2) Bollman, J. L., Cain, J. C., and Grindlay, J. H. (1948): The techniques for the collection of lymph from the liver, small intestine or thoracic duct of the rat. J. Lab. Clin. Med., 33, 1349-1352.

3) Folch, J., Lees, M., and Sloane-Stanley, G. H. (1957): A simple method for the isolation and purification of total lipids from animal tissues. J. Biol. Chem., 226, 497-509.

4) Fletcher, M. (1968): A colorimetric method for estimating serum triglyceride. Clin. Chim. Acta, 22, 393-397.

5) Zak, B. (1957): Simple rapid microtechnic for serum total cholesterol. Am. J. Clin. Pathol., 27, 583-588.

6) Bartlett, G. R. (1957): Phosphorus assay in column chromatography. J. Biol. Chem., 234, 466-468.

7) Itaya, K., and Ui, M. (1965): Colorimetric determination of free fatty acids in biological fluids. J. Lipid Res., 6, 16-20.

8) Lowry, O. H., Rosebrough, N. J., Farr, A. L., and Randall, R. J. (1951): Protein measurement with the folin phenol reagent. J. Biol. Chem., 193, 265-275.

9) Dole, V. P. (1956): A relation between nonesterified fatty acids in plasma and the 
metabolism of glucose. J. Clin. Invest., 35, 150-154.

10) Davis, B. J. (1964): Disc electrophoresis-II. Method and application to human serum proteins. Ann. N. Y. Acad. Sci., 121, 404-427.

11) Cardell, R. R., Jr., Badenhausen, S., and Porter, K. R. (1967): Intestinal triglyceride absorption in the rat. An electron microscopic study. J. Cell Biol., 34, 123-155.

12) Strauss, E. W. (1968): Morphological aspects of triglyceride absorption, in Handbook of Physiology, ed. by J. Field, Am. Physiol. Soc., Sect. 6, 3, Washington, D. C., pp. 1377-1406.

13) Friedman, H. I., and Nylund, B. (1980): Intestinal fat digestion, absorption, and transport. A review. Am. J. Clin. Nutr., 33, 1108-1139.

14) Palay, S. L., and Karlin, L. J. (1959): An electron microscopic study of the intestinal villus. II. The pathway of fat absorption. J. Biophys. Biochem. Cytol., 5, 373-384.

15) Strauss, E. W. (1966): Electron microscopic study of intestinal fat absorption in vitro from mixed micelles containing linolenic acid, monoolein, and bile salt. J. Lipid Res., 7, 307-323.

16) Higgins, J. A., and Barnett, R. J. (1971): Fine structural localization of acyltransferase. The monoglyceride and $\alpha$-glycerophosphate pathways in intestinal absorptive cells. $J$. Cell Biol., 50, 102-134.

17) Redgrave, T. G. (1973): The role in chylomicron formation of phospholipase activity of intestinal Golgi membranes. Aust. J. Exp. Biol. Med. Sci., 51, 427-434.

18) Friedman, H. I., and Cardell, R. R., Jr. (1972): Effects of puromycin on the structure of rat intestinal epithelial cells during fat absorption. J. Cell Biol., 52, 15-40.

19) Takahashi, Y., Mizunuma, T., and Kishino, Y. (1982): Ultracytochemical studies on fat absorption by choline-deficient rats. Acta Histochem. Cytochem., 15, 90-101. 